\title{
Exploring Creative Environments through the Child's Lens
}

\author{
Deirdre Grogan*, Joan Martlew \\ University of Strathclyde, Glasgow, UK \\ Email: * d.grogan@strath.ac.uk
}

Received 14 June 2014; revised: 2 August 2014; accepted 20 August 2014

Copyright (C) 2014 by authors and Scientific Research Publishing Inc.

This work is licensed under the Creative Commons Attribution International License (CC BY). http://creativecommons.org/licenses/by/4.0/

\section{(c) (i) Open Access}

\section{Abstract}

There is strong governmental support within the UK to develop creativity and emphasise the importance of its role in learning and teaching. Sharp (2003) identified issues, gaps and priorities for further research that looked at the impact on children of working with professional artists in terms of their creativity. This paper explores the initial findings of an evaluation report conducted by a university research team, exploring the creative performances designed by Starcatchers, an organisation developing performing arts experiences for children aged birth to 4 years. The research team consisted of four action researchers who were each attached to an artist in residence working in four theatre venues across Scotland. The artists involved represented four different art domains: puppetry, visual arts, artistic experiences informed by playing therapy and installation work. The researchers collaborated with the artists to observe children's engagement, provide feedback, discuss projects, and record the processes of project development. This paper seeks to explore the artists' experience of designing and implementing participative performance events and the nature and processes of working with young children in performing arts. It focuses on an exploration of the creative learning processes which were developed by the artists in residence to promote children's creativity and involvement in the visual arts. The role of the artist is examined and key aspects are suggested with a view to enhancing the creative learning experiences provided for children within educational contexts, indicating points for consideration by adults charged with the responsibility of planning and developing environments which support young children's creativity.

\section{Keywords}

Starcatchers, Creative Environments, Educational Artist-in Residence, Young Children's Creativity

\footnotetext{
${ }^{*}$ Corresponding author.
} 


\section{Introduction: Current Context}

Creativity is an area of great interest in the current educational context within the U.K. Creativity in thinking and learning is not a new phenomenon and has often been debated and discussed not only within education but also the field of arts, culture, and policy makers. Robinson (2010) suggests that that education may reduce the creativity of children and Trevarthen (2011) states that all children are born with the potential to be creative. The publication of the All Our Futures Report (NACCCE 1999) and the subsequent Scottish report Creativity in Education (SCEAG 2001) has led to an increased awareness of the need for a greater emphasis on the role of creativity in the lives and education of young children. There is evidence to suggest creativity is enhanced when children are given elements of choice and control of their learning, with a balance between structure and freedom (Gandini et al. 2005, Ewing 2009, Davies 2011). If children are understood to be active participants in their world, as creative co-constructors of their world and as individuals with their own views of the world (Jans, 2004) the extent to which they therefore have opportunities to fulfill this disposition is determined in part by the environments in which they spend their earliest years.

In 2000 creativity was identified as being at the centre of a whole-school ethos and Creative Development was identified as one of the six curricular areas in the early years' curriculum in England (Curriculum Guidance for the Foundation Stage, DfEE/QCA, 2000). The QCA later published Creativity: Find it, Promote it (QCA, 2005) which was based on research into creativity in the primary curriculum. Craft (2000: p. 38) identify creativity as "a state of mind in which all intelligences are working together" which reflects the holistic nature of the way in which young children learn (David, Goouch, Powell and Abbott, 2003). Lassing (2009) stated that young children should be provided with a variety of learning experiences enabling them to develop long lasting creative skills and thinking; in addition to variety children also require sufficient time and opportunities to explore such experiences. Cremin et al. (2006) identified that children's creative thinking and learning developed when provided with a flexible approach that took consideration of the children's thoughts and ideas. Runco, 2007 highlighted that creativity enhanced children's learning and development in language, decision making and imagination. The ability to make decisions is based on making connections between memories and link with the new experience in order to solve problem (Claxton and Lucas, 2004).

Sharp (2003) undertook a review in the UK which sought to present an overview of the current state of research and thinking on the relationship between the arts and creative development in young children (aged three to six years). She aimed to identify issues, gaps and priorities for further research and found little work at that time that looked at the impact on children of working with professional artists in terms of their creativity. She recommended that there should be additional research looking at many aspects of creativity with young children including the role of professional artists working with young children. The McMaster report (2008: p. 7) has potentially refocused thinking on creative learning as a "new cultural offer" identifying the dual nature of the creative process which involves young children as both spectators and participants.

In Scotland, there is also strong government support to “... develop a shared vision for creativity and its role in learning and teaching in the context of Curriculum for Excellence (Scottish Executive, 2004) highlighting the importance of the creative skills of children and young people, and the characteristics which should be promoted by creative learning and teaching in the arts and culture, and across the curriculum” (Scottish Parliament 2010: 6). Grainger et al. (2006) have suggested that creativity is not restricted to any particular curricular area but is instead an essential element to many subjects as it promotes the ability to solve problem and produce novel ideas. This notion is not restricted to the formal education system but is also applicable to other organisations and projects which may involve, not only artistic and imaginative thinking but the ability to be resourceful, innovative and inventive.

\section{Starcatchers}

Starcatchers is one such innovative project which, funded through the Creative Scotland National Lottery Inspire Fund, works in partnership with artists, arts venues child-care settings and families to experiment artistically with audiences of very young children, to encourage their participation and to develop exciting, inspiring performing arts experiences for children aged 0 - 4. One of the main aims of Starcatchers is that "Creativity has a fundamental role in supporting early child development” (Starcatchers, 2011).

The project was built around four artists in residence who each worked for a year in a theatre venue in Scotland aimed with engaging young children and their families in a range of arts related performance experiences in 
their local community.

The main elements from each of these four environments will be explored in this paper in order to extract the key features of creative learning. Laevers and Moons (1997) indicate that the environment should provide children with opportunities to learn by providing a safe context; peer collaboration and child initiated learning experiences which provide children with ownership and decision making.

An important element of developing children's creativity was described as adults and teachers providing a "safe" structure thereby encouraging children to take risks, to question and to think critically and creatively (Halsey et al. 2006). There are however challenges for educators in providing opportunities for creative experiences for children in a context where the funding of these may well be in competition with other curricular areas and determined by assessed outcomes (Walsh, 2010).

Reason (2008) uses the vehicle of philosophical enquiry to support children's engagement with theatre and to deepen their experiences. He argues that theatre made for children should observe that "A marker of quality in a cultural experience is its enduring resonance as it engages its audience intellectually, imaginatively or emotionally" (Reason, 2008: p. 1). The Starcatchers approach is somewhat different in that its purpose is to co-create arts experiences with children and where possible with families and early educators. There has been limited research about the experience of theatre for very young children however this project provides an insight into performances involving children from birth to four years old. The Starcatchers project team instigated this age profile as it links to current Scottish early years policy expressed in the Early Years Framework (Scottish Government, 2008) in which a clear aim is to intervene early with families from birth.

\section{Methodology}

The research took the form of a small scale exploratory study focused on the development of the design of each performance by the artists in residence. An initial review was carried out by the research team to position the Starcatchers Project in order to shape an informing theoretical framework for the research. The data was gathered through the following methods; semi-structured interviews with the artists, reviewing the artists' blogs and narrative observations, photographs and video footage of each performance. Each researcher was responsible for observing their partner artist in residence, sharing observations and reflections with the artist exploring ways in which they developed the use of the environment as a means to developing young children's engagement with performance and creativity.

Analysis of the artists' blogs enabled the researchers to gain "some understanding of the creator's intentions and their impact on the audience" (Pavis, 2003: p. 10) and allowed the researchers to identify emerging themes in relation to the children's engagement signals.

The researchers identified key themes from the artists own research tools which focused on atmosphere, aesthetics, process, audience engagement, children's involvement, and environments (Dunlop, McNaughton, Grogan, Martlew and Thomson, 2011).

The observations were carried over throughout the duration of each performance using time sampling and target child sampling. The performance was scanned at 10 minute intervals and the observer noted key point $\mathrm{s}$ related to the environment, the actions of the performers and the children. The target child observations (Sylva et al., 1980) recorded the child's engagement signals throughout performance on a 4 minute sample of randomly selected children. Each of the target child observations lasted for approximately five minutes, focusing on what the child was doing, who was with her/him, interactions with other children or adults and behavioural indicators of engagement. A judgement was made by the researcher regarding the level of the child's engagement using a set of seven signals-“attuned”, "absorbed”, "mirroring”, "responsive”, "interactive”, "instigative” and "experimental". These signals were developed during a shared research team analysis of the PEEP production recordings (Starcatchers Pilot Project, 2009) expanding a set of original types of engagement "absorbed engagement" and "interactive engagement" (Young \& Powers, 2008). These signals informed the observations and formed the basis of coding the narrative records, photographs and video episodes. Each observation signal was scored against the following criteria: apprehensive, tentative, attuned, secure or confident (Dunlop et al., 2011). See Table 1.

The semi-structured interviews with the artists focused on the following four headings: Your project and you; Working collaborations; Working with young children and your learning and development. The design of the interview questions were created collaboratively with the Starcatchers team to ensure that the data would provide 
Table 1. Signal descriptors.

\begin{tabular}{cl}
\hline Signals & Descriptor \\
\hline Attuned & Watching, tracking and cued in to what is going on \\
Absorbed & Intense attention for a period and ignores any distraction \\
Mirroring & Watching and reciprocating through approximately repeating or copying \\
Responsive & $\begin{array}{l}\text { Positive body language, social referencing, following verbal and non-verbal } \\
\text { narrative and smiling/reaching/nodding }\end{array}$ \\
Interactive & Physically responding and doing, in 2 way exchange with another \\
Instigative & Provokes action in others through own responsive action or verbalisation \\
Experimental & Taking individual action with materials, props, instruments \\
\hline
\end{tabular}

a full account of the artist's thought processes during the planning and implementation of the performance. The semi-structured interview method was selected in order to explore the artist's thinking in terms of planning, designing and implementing and evaluating each performance and used to identify common features. These common features included the importance of the environment, enhancing creativity through the availability of resources, affording children time to ponder and explore and the relationship between the artist and the children. The average interview time was 35 minutes and all interviews conducted were transcribed and this data was categorised using NVivo 8 (2008), a qualitative data analysis (QDA) computer software package) produced by QSR International. The relationship between the key features was then identified and led to the final analysis (Marshall and Rossman, 1995) indicating the design of the learning environment and the extent that this impacts on the child's creativity. The vignettes described below provide an insight into the performance design and reflect changes made by the artists in response to children's reactions. The artists' reflections on developing theatre for very young children are also included to strengthen the voice of the artist and to provide insight into the artists' creative thinking. It is useful to describe these experiences and how they became productions through the artists own words in order to provide context for the discussion that follows.

\section{Vignettes from the Starwatchers' Artists-A Documented Account of Four Performances}

\subsection{Artist 1 in Residence at the Byre, St Andrews Round in Circles}

Round in Circles, which is illustrated in Figure 1 was an interactive performance for 1 - 3 year olds, was developed through collaboration with a musician, designer and an assistant director, feedback from pilot audience of nursery children as part of the development process. The main focus of the performance was the relationship between performance and creative play using puppetry, objects, live music and percussion to open up a circular world encouraging children to use their imaginations. The artist and the development team experimented with a variety of circular objects, including hoops, drums and discs, finding ways to play and interact with them. They then visited local nurseries with these objects and shared the "play with objects" inviting the children to play with the materials. The title of the performance Round in Circles was decided due to the artist's interest in rotational and trajectory schematic development and suspected that this "circular" focus would be interesting for the children as such schemas are often features of learning behaviours in young children (Athey, 2008). As the children explored and played with the objects, the artist and her collaborators' observations of the children's responses were crucial in shaping the decisions about the final theatrical production. They observed pattern in the children's behaviour and interesting themes or moments. The artist describes the next stage of the design as "the craft" of shaping the material into something poetic, theatrical and beautiful, developing an environment creating fragments of story around an action, building to a climax, making something bigger or altering position of objects. At this point a designer, a director and a lighting designer became involved to create a suitable creative environment. This was a complex process, carried out over an extended period of time in four different nursery settings. Once the production was finalized and performed to a "live" audience children were invited at certain points during the performance to play with objects shown to them. The children's interaction with the materials changed in response to each child's creative thinking and was a fundamental part of the experience.

Another important aspect of the performance was creating an interactive environment. The artist had viewed 


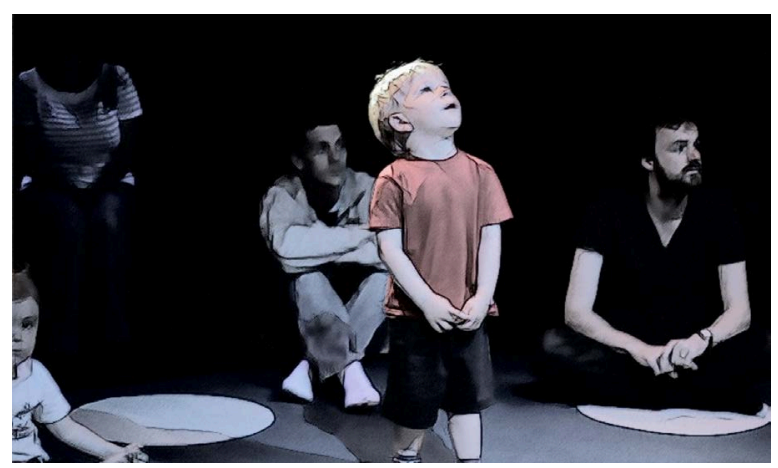

Figure 1. Round in Circles.

other Early Years theatre productions and noted that a child would often physically leave their seat and try to get on the stage, handling the props, as if they were trying to tell the artists something. She wanted to satisfy this urge, by creating something where it wouldn't be disruptive to the performance if they did join her on stage. This illustrated the theme of Round in Circles as it completes a cycle where the artist initiates the performance but ensures collaboration and participation to a level which results in children being part of the performance experience and communicating their ideas and feelings through their active participation.

\subsection{Creative Learning Environment: Artist 2 in Residence at Tramway, Glasgow Sparkalator}

Sparkalator was also an interactive performance aimed for children aged between three and five years. The performance took a group of young children on a journey from their nursery into the Tramway theatre which is shown in Figure 2. They were met by a very grey character that was not very happy. She gave the children individual cloaks and tickets for the Sparkalator. The Sparkalator was the lift within the theatre however the artist in residence wanted to use an everyday environment and alter it to provide a creative experience for children. The children were guided into the lift which had been transformed into the Sparkalator complete with sounds and buttons. When the lift doors opened upstairs, the children had been transported into a bright, light world with cushions and colour. Using film, music and play, the children helped bring sparkle back into the life of the grey character they had met downstairs, transforming her into a happy, bright character. The artist included a focus on making the entrances to the spaces inviting, creating atmosphere through props such as the individual cloaks and tickets, making sure children were in close proximity to the action. She also used colour, sound and light to provoke the senses; signposting through light, movement and sound where children should give their attention, giving the children opportunities to discover properties through hands on or active participation so sharing the artists' props or “tools”. The artist in her semi-structured interview with the researcher stated that she felt liberated by the importance of visuals over words for young children. Her work had always had a narrative element, and she wanted to create a new enticing dream world to be explored. She hoped to spur imagination, inspire, encourage interaction with different people and provoke thought and discussion in others. Throughout the research period the artist's aim was to stimulate young children's creative thinking in ways which did not depend on the spoken word but instead focused on alternative ways of communication.

\subsection{Creative Learning Environment: Artist 3 in Residence at the Carnegie Hall, Dunfermline and the Lochgelly Centre, Fife, Oops a Daisy}

Oops a Daisy was designed as a piece which was purely about movement and sound and was based around an everyday action that young children regularly; dancing, clapping and falling down which is highlighted in Figure 3 i.e. Oops a Daisy. The artist worked along with a choreographer, professionally trained dancers and a musician to create action and movement that would appeal to not only very young children and also to the accompanying adults. The performance aimed to engage a wide age range (birth to four years) on different levels. The very young children enjoyed the movement, colour and sound; the older age enjoyed the performers, the interactive clapping and the opportunity to dance from within the audience and to discover the "Oops a Daisy" moments. 


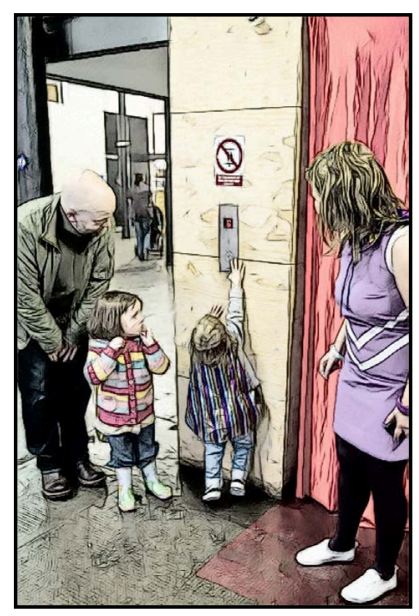

Figure 2. Sparkalator.

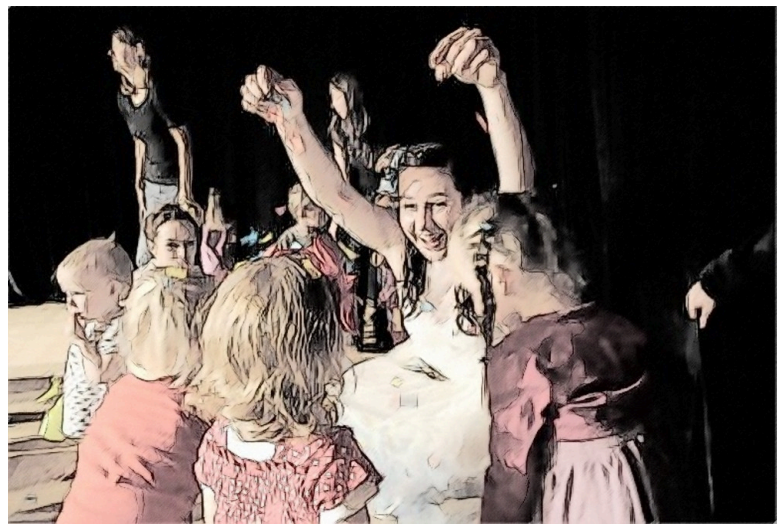

Figure 3. Oops a Daisy.

\subsection{Creative Learning Environment: Artist 4 in Residence at the Platform, Easterhouse, Glasgow-First Light}

First Light is set on a staged area children can be seen in Figure 4, within a circular white tented space the audience of very young children and their parents and carers are introduced to the performance by the sound of soft whistling and guitar music. This atmosphere sets the tone for the appearance of Dawn, who is about to wake up the world. Dawn smiles and lights up the sky, accompanied by the sounds of tweeting birds, a crowing cockerel, mooing cows and barking dogs as they herald the start of a new day.

Dawn meets the Man in the Moon as the night changes to day and they pass the baton of night to day to one another using a blend of dance, acrobatics and mime. This movement is supported and enhanced by a moving backdrop of flickering stars and billowing clouds. The story progresses and the artists use exaggerated movements or surprised expressions to convey the continuing plot. The set changes from day to night to day, in-corporating the use of everyday objects such as a mirror, an apple, a hair brush, a moon, clouds and stars. The performance is enhanced with the use of both soothing and energetic music, matched to the movements of the actors and the developing storyline.

\section{Artists' Reflections on Each of the Performances}

\subsection{Artist 1-The Byre}

“... Exciting, humbling, beautiful and profound.

To create theatre for children or for adults? Or with children in the room or with adults in the room? I'll answer the first: 


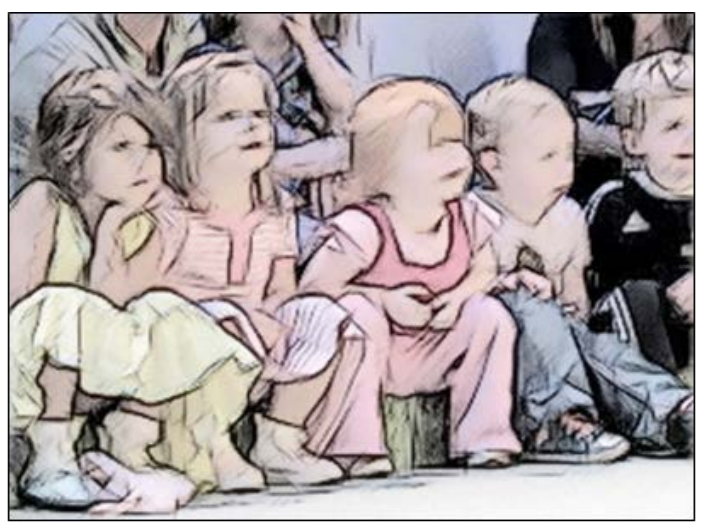

Figure 4. First light.

"You need to take good care of very young audiences-things like how the audience enters the space, how they sit, how close they are to the action, how dark or light you can make it all require special attention. I'm also interested in how interaction can be satisfying for under $4 \mathrm{~s}$ who know no boundaries of how they are supposed to behave in the theatre and are far more gentle than older children-often needing longer pauses to allow them to contribute. However they don't come alone and I want the play to work on a level for adults as well. If the play has the right heart to it, then it should work for both."

\subsection{Artist 2-Carnegie Hall and the Lochgelly Centre}

"I wanted to create a show which felt spontaneous and fresh, and one which allowed the audience space to respond to with their own ideas. I found early on that it was important when offering dance to such a young age that a narrative in some way was of importance. A hook was required in order for the children to invest in the piece and the importance of character and performers that they could relate to began to emmerge (sic) and one I would like to develop further. The presentation of the piece went very well with some families returning to see it again based on their own enjoyment and upon the request of their children. It was demonstrated through feedback that the show was an enjoyable experience for both. The show engaged the wide age range of $0-4$ years on different levels. The very young enjoyed the movement and colour and sound, the older age enjoyed the characters, the interactive clapping and the opportunity to dance from within the audience and to discover the 'Oops a Daisy' moments. At the end everyone enjoyed the opportunity to explore the 'theatre space', the objects and the performers."

\subsection{Artist 3-Tramway}

"Once a year a Sparkalator gives groups of children the chance to visit the sky... I've heard a rumour its on its way here... Sparkalator was made with the nursery group I've been working with in Pollockshields East in mind. I wanted to make it as personal as possible. It began from an idea that came up in the nursery of turning the tap off on the rain in Glasgow. It was a particularly unsparkly grey morning and at 9am I set off to meet the nursery kids to bring them along the road to the Tramway - it was going to be for most, if not all of them, their first time in the building. Rhona and I tied helium balloons along the route to the Tramway from the nursery. When we got to the nursery I painted their 'ticket' on their cheeks (a bluish silvery lighting streak). We walked along hand in hand counting 1 balloon, 2 balloons-hey wait a minute... there's a guy across the road making a get away with the rest of them. Oh well kids.... We entered the Tramway and arrive at the Sparkalator, on base level, and we meet Xana, the lift attendant/air hostess. She is an adult... and she has lost her sparkle. We go up in the Sparkalator, the wee nervous excited faces look up to me-like 'Where are you taking us Katy?' We come out at the sky, we try things, and make things to help Xana get her sparkle back-we are able to view her down on earth on the TV. Anyway I'll not give it all away.”

\subsection{Artist 4-Platform}

"At the end of each week we were devising and rehearsing the show we invited an audience of local children in- 
to the venue to watch our work-these sessions hugely informed the decisions we made in making the show and the presence of the children was important and welcome.

For the audience-I wanted First Light to be an exciting and magical first experience of performance for the very youngest of children and the adults that accompany them into the venue. I wanted there to be lots of interesting pictures (created by the performers and designers) sounds and moments of communication to engage our young audience. It was also important to me that the production "made sense" to the watching adults too.

.... Personally I was keen to create a show that was well designed and have the chance to use all the fantastic lighting and sound equipment available to me at the venue. It was also important to me and my relationship with the venue that I attempt to create a solid piece of work with strong production standards and put it on the main stage. In doing so it was my aim to prove to my colleagues and other members of staff in the building that theatre for the very young does work and can be something for us all to support and advocate... One thing I am sure about however is that we really benefitted from presenting our ideas to an invited audience at the end of each week that we worked together. This audience was made up of children, parents and carers from X Family Centre and $Y$ nursery. The reactions of both children and adults informed our decisions greatly and I'd like to thank both groups for agreeing to come along to Platform and help."

\section{Discussion}

The perceptions of the artists above provides evidence of the ways in which creative projects such as Starcatchers incorporate the voice of the child in developing innovative and engaging creative experiences. All four artists employed a variety of interactive and responsive performances which encouraged the children to develop their creativity. Addison et al. (2010), Bancroft et al. (2008), and Jeffrey (2006) highlight that there should be space within a creative learning environment that can be flexible in order to promote creativity. Areas within the environment should be flexible and adaptable change in order to develop children's imagination and children should be co-participants involved in the planning of the performances in order to develop their confidence, ownership and their planning skills. It can be seen from the description of the Round in Circles performance that the artist was not imposing her own creative ideas on the audience or the other performers but that her original ideas were transformed and shaped through the collaborative process of working with nursery children. This process continued throughout the development and rehearsal period. The artist invited children and their parents and or carers to the development and rehearsal sessions that took place within the performance space. The reactions and responses from each of these sessions informed the decisions about the finished theatre performance. The environment therefore became a pedagogical tool conveying abstract experiences, sensory stimulation and narrative. This was evident in the way in which the children were free to explore the sensory environment, create their own learning path without direction from the adults. Through this the children created their own storyline, creation or design. The level of ownership afforded to the children resulted in a unique and personal creative process which could be further developed by the children.

This pedagogy reflects the philosophy of Malaguzzi (1996) which underpins the curricular approach of Reggio Emilia. Such approaches emphasise the importance of perceiving the environment as "the third educator" where social, physical and cognitive development take place. Vecchi (2010) clearly stated the importance of light, colour, sound to allow the children to create their own environment.

Katz (in Abbott and Nutbrown, 2001) wrote that there was no evidence in Reggio Emilia schools "that all children were subjected to instruction at the same time, of having to create the same pictures or other art products—a common sight in our schools...” (p. 11). In the learning environment there is some evidence that, in order to stimulate creative response from children, learning experiences need an element of novelty (Rutland and Barlex, 2008) however the element of novelty is not defined but states that children should be motivated and responsive to the created environment as exciting for the children. The Starcatchers project aimed to challenge what could be created for young children in a way that directly involves and includes them and the important people around them—-parents, carers and grandparents. Its design was based around this dual collaboration and aimed to create tailor-made and unique bespoke pieces of theatre.

One point that is stressed in the Starcatchers project is the fact that the learning experience should be linked to a context, with stimulating starting points which motivate the children. This was highlighted in the Sparkalator with the use of the lift, a common setting for many children but which was introduced with a problem for the children to solve. The environment was designed in order to give children choice, be creative and to explore 
both light and sound through their journey within the Sparkalator.

The Figure 5 illustrates the three main components of the Starcatchers perceived design, the children; the environment and the artist. From the researchers observations the components become effective in developing creative thinking when at least two are present. Observations of the children and the environment highlighted that the children demonstrated the instigative signal (provokes action in others through own responsive action or vocalisation, see Table 1) and interacted with resources. Observations of the artist and the children indicated that the children mirrored (watching and reciprocating through approximately repeating or copying, see Table 1) the artist's actions and interactions within the performance. However, when all three components were present the children were fully engaged and evidence was recorded of the children experimenting (taking individual action, with materials, props and instruments, see Table 1) therefore a high level of creativity.

The researchers' observations and the artists' reflections from the project suggest that children's creativity can be developed by careful consideration of resources which allow children to be flexible in their thinking and creation and by adapting and modifying these resources based on close observations of children's participation and engagement with them in the early stages of performance development. Csikszentmihalyi (1997: p. 23) asserted that, "creativity does not happen inside people's heads but in the interaction between a person's thought and a sociocultural context”.

Therefore an examination of the sociocultural context in which families live can help develop children's creativity, shaping the physical environment and the available resources in ways that propose and encourage new ways to interact with familiar spaces and provide children with opportunities to experiment and explore these resources without direct adult, so often the case in many adult child interactions.

Each of the performances consisted of an environment which offered space, actors/artists and music. The children were offered time to scan the environment prior to their involvement and participation and the opportunities to explore aspects of their creativity, allowing the children to "make" but the product was not suggested by the adult, therefore the children could shape their own learning.

Important factors in developing children's creativity were stated as being a stimulating environment, a breadth of learning and the role of resources (Martlew and Grogan, 2013). These factors were interwoven into each of the performances. This supports Whitehead's identification of creativity being supported by meaningful experiences, active participation, engagement in imaginative play and feelings of emotional security (1997: p. 65).

The key elements that have arisen from the analysis of the environments highlight the importance of choice for children in order to allow them to follow their line of design or thought, as stated by Northcott, Miliszewska and Dakich "creativity can be defined as a combination of thinking and innovation" (2007: p. 761). To enable this, children need to be stimulated in the learning environment and have time to be innovative in their designs. A child who thinks creatively can adapt and amend their own design through taking time to reflect on the process and to discuss with an adult or another child what they have been doing. This was observed by the researchers in the observed Starcatchers performances. There is a strong argument to develop creative learning environments (Scottish Executive, 2004) in order to encourage creative thought in young children (Reid and Petocz, 2004).

The Starcatchers data clearly illustrates the importance of the provision and the opportunities for exploration by the children in each setting. The artists were aware of the need for a flexible environment which provided the stimulus for children's developing creativity.

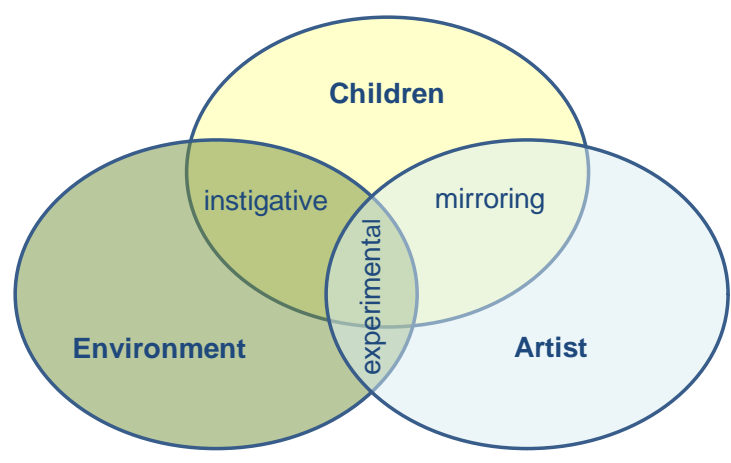

Figure 5. Creative framework. 


\section{Conclusion}

From this study key characteristics identified from the Starcatchers settings which contribute to designing learning environments that are most effective in promoting children's creative thinking creativity in young children have been identified as the following: the environment; availability of resources; time; relationship between artist and child. However one of the most important features was a familiar context, such as a lift or traditional rhymes presented in a novel and creative way by the artists. This ensured that the children were comfortable in the environment and more responsive to the performance. This links to the work of Ashby, Isen and Turken (1999) which indicate that people become more creative when they feel comfortable and happy. Each coded observation outlined that where children were most experimental they were also confident and secure which enhanced the level of creativity (Dunlop et al., 2011).

In conclusion it can be suggested that the power of the child being instrumental in contributing to the design of the creative learning environment should ensure that children become familiar with opportunities, resources, potential learning with awareness and a confidence that the adult will support their creative thinking without over directing or steering their learning in a prescribed manner. This negotiated environment allows children to take risks, discover new ways of thinking and persevere with their creative explorations. Children who are given time and supported independence to develop creative thinking in the early formative years may be able to think creatively in all aspects of their education and perhaps even in their chosen careers. Edelman (2007) stated that "imagination is relatively free from objective constraints", therefore each performance provided the opportunity for the children to extend their own creativity without the need to produce an expected end product.

Finally, if we stand back and take time to observe the children within the creative learning environment we will gain knowledge about how young children think and learn and impact on our own pedagogical beliefs and our own practice. "Creating a harmonious, meaningful environment in space and time helps you to become personally creative” (Csikszentmihalyi, 1996: p. 146).

\section{Acknowledgements}

We would like to extend our thanks to the Starcatchers Project Team.

\section{References}

Addison, N., Burgess, L., Steers, J., \& Trowell, J. (2010). Understanding Art Education: Engaging Reflexively with Practice. London: Routledge/Falmer.

Ashby, F. G., Isen, A. M., \& Turken, A. U. (1999). A Neuropsychological Theory of Positive Affect and Its Influence on Cognition. Psychological Review, 106, 529-550. http://dx.doi.org/10.1037/0033-295X.106.3.529

Athey, C. (2008). Extending Thought in Young Children. London: Sage.

Abbott, L., \& Nutbrown, C. (2001). Experiencing Reggio Emilia: Implications for Preschool Provision London OU. Buckingham.

Bancroft, S., Fawcett, M., \& Hay, P. (2008). Researching Children Researching the World. Stoke on Trent: Trentham.

Claxton, G. L., \& Lucas, B. (2004). Be Creative: Essential Steps to Re-Vitalize Your Work and Life. London: BBC.

Craft, A. (2000). Creativity across the Primary Curriculum. London: Routledge

Cremin, T. (2006). Creativity, Uncertainty and Discomfort: Teachers as Writers, Cambridge Journal of Education, 36, 415433. http://dx.doi.org/10.1080/03057640600866023

Csikszentmihalyi, M. (1996). Creativity. New York: Harper Collins.

David, T., Goouch, K., Powell, S., \& Abbott, L. (2003). Birth to Three Matters: A Review of the Literature: Compiled to Inform the Framework to Support Children in Their Earliest Years. Department for Education and Skills, Research Report RR444.

http://webarchive.nationalarchives.gov.uk/20130401151715/https://www.education.gov.uk/publications/eOrderingDownlo ad/RR444.pdf

Davies, D. (2011). Teaching Science Creatively. London: Routledge.

Dunlop, A., McNaughton, M., Grogan, D., Martlew, J., \& Thomson, J. (2011). Live Arts Arts Alive. Starcatchers Research Project Main Report, Glasgow: University of Strathclyde.

Ewing, R. (2009). Creating Imaginative, Practical Possibilities in K-6 English Classrooms. In J. Manuel, P. Brock, D. Carter, \& W. Sawyer (Eds.), Imagination Innovation Creativity: Revisioning English in Education (pp. 173-182). Sydney: Phoe- 
nix Publication.

Jeffrey, B. (2006). Creative Teaching and Learning: Towards a Common Discourse and Practice. Cambridge Journal of Education, 36, 399-414. http://dx.doi.org/10.1080/03057640600866015

Gandini, L., Hill, L., Cadwell, L., \& Schwall, C. (2005). In the Spirit of the Studio: Learning from the Atelier of Reggio Emilia. New York: Teachers College Press.

Grainger, T., \& Barnes, J. (2006). Creativity in the Primary School Curriculum. In J. Arthur, T. Grainger, \& D. Wray (Eds.), Learning to Teach in the Primary School (pp. 209-252). London: Routledge.

Halsey, K., Jones, M., \& Lord, P. (2006). What Works in Stimulating Creativity amongst Socially Excluded Young People? http://www.nfer.ac.uk/nfer/publications/NES01/NES01.pdf

Jans, M. (2004). Children as Citizens: Towards a Contemporary Notion of Child Participation. Childhood, 11, 27-44. http://dx.doi.org/10.1177/0907568204040182

Laevers, F., \& Moons, J. (1997). Enhancing Well-Being and Involvement in Children: An Introduction in the Ten Action Points. Leuven: Centre for Experiential Education.

Malaguzzi, L. (1996). The Hundred Languages of Children: The Reggio Emilia Approach to Early Childhood Education. New Jersey: Ablex Publishing Corporation.

Marshall, C., \& Rossman, G. B. (1995). Designing Qualitative Research. London: Sage Publications.

Martlew, J., \& Grogan, D. (2013). Reach for the Stars! Creative Engagement with Young Children. Early Child Development and Care, 183, 1029-1041.

National Advisory Committee on Creative and Cultural Education (NACCCE) (1999). All Our Futures: Creativity, Culture and Education: Report to the Secretary of State for Education and Employment. Sudbury: Department for Education and Employment.

Northcott, B., Miliszewska, I., \& Dakich, E. (2007). ICT for (I)nspiring (C)reative (T)hinking. The ASCALITE 2007, Singapore.

Pavis, P. (2003). Analyzing Performance: Theatre, Dance and Film. Ann Arbor, MI: Michigan University Press.

QCA (2005). Creativity: Find it, Promote It!-Promoting Pupils' Creative Thinking and Behaviour across the Curriculum at Key Stages 1, 2 and 3-Practical Materials for Schools. London: Qualifications and Curriculum Authority.

Qualifications and Curriculum Authority/Department for Education and Employment (2000). Curriculum Guidance for the Foundation Stage. London: DfEE/QCA.

Reason, P., \& Riley, S. (2008). Co-Operative Inquiry: An Action Research Practice. In J. Smith (Ed.), Qualitative Psychology: A Practical Guide to Research Methods (2nd ed.). London: Sage Publications.

Reid, A., \& Petocz, P. (2004). Learning Domains and the Process of Creativity. Australian Educational Researcher, 31, 45-62. www.aare.edu.au/aer/online/40020d.pdf http://dx.doi.org/10.1007/BF03249519

Robinson, K. (2010). Out of Our Minds: Learning to be Creative (2nd ed.). Oxford: Capstone.

Runco, M. A. (2007). To Understand Is to Create: An Epistemological Perspective on Human Nature and Personal Creativity. In R. Richards (Ed.), Everyday Creativity and New Views on Human Nature (pp. 91-107). Washington, DC: American Psychological Association.

Rutland, M., \& Barlex, D. (2008). Perspectives on Pupil Creativity in Design and Technology in the Lower Secondary Curriculum in England. International Journal of Technology and Design Education, 18, 139-165. http://dx.doi.org/10.1007/s10798-007-9024-6

Scottish Creativity in Education Action Group (2001). Creativity in Education. Edinburgh: SCEAG.

Scottish Executive (2004). A Curriculum for Excellence. Edinburgh: Scottish Executive.

Scottish Parliament (2010). Education and the Arts, Culture \& Creativity: An Action Plan. http://www.scotland.gov.uk/Topics/Education/Schools/curriculum/ACE/expactionplan

Sharp, P. C. (2003). What's Important in Early Years Education? Some Messages from Research. TOPIC, Issue 30, Item 7.

Starcatchers Pilot Project (2009). PEEP: Starcatchers Previous Performances.

Sylva, K., Roy, C., \& Painter, M. (1980). Child Watching at Playgroup and Nursery School: Oxford Pre-School Research Project. London: Grant McIntyre.

Trevarthen, C. (2011). What Young Children Give to Their Learning, Making Education Work to Sustain a Community and Its Culture. European Early Childhood Education Research Journal, 19, 173-193. http://dx.doi.org/10.1080/1350293X.2011.574405

The Scottish Government (2008). A Guide to Getting It Right for Every Child. Edinburgh: The Scottish Government. 
Vecchi, V. (2010). Art and Creativity in Reggio Emilia: Explaining the Role and Potential of Arteliers in Early Childhood Education. London: Routledge.

Walsh, M. (2010). Multimodal Literacy: What Does It Mean for Classroom Practice? Australian Journal of Language and Literacy, 33, 211-239.

Young, S., \& Powers, N. (2008). Starcatchers Pilot Study Final Report: See Theatre: Play Theatre. 
Scientific Research Publishing (SCIRP) is one of the largest Open Access journal publishers. It is currently publishing more than 200 open access, online, peer-reviewed journals covering a wide range of academic disciplines. SCIRP serves the worldwide academic communities and contributes to the progress and application of science with its publication.

Other selected journals from SCIRP are listed as below. Submit your manuscript to us via either submit@scirp.org or Online Submission Portal.
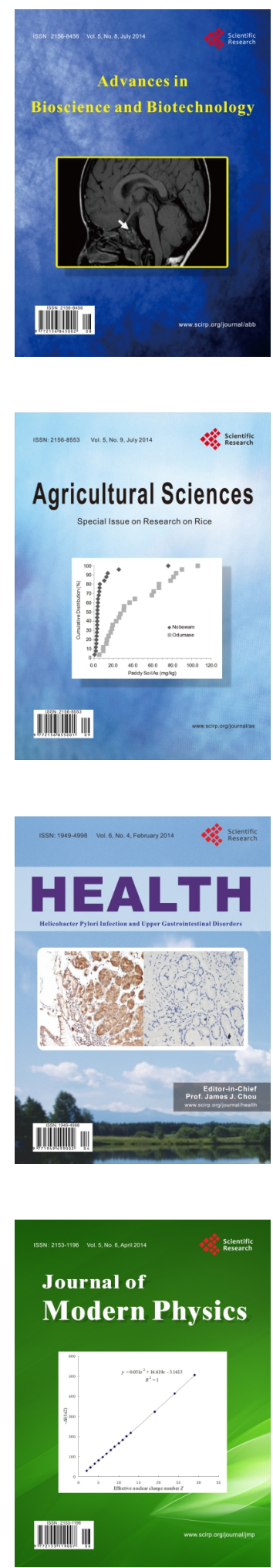
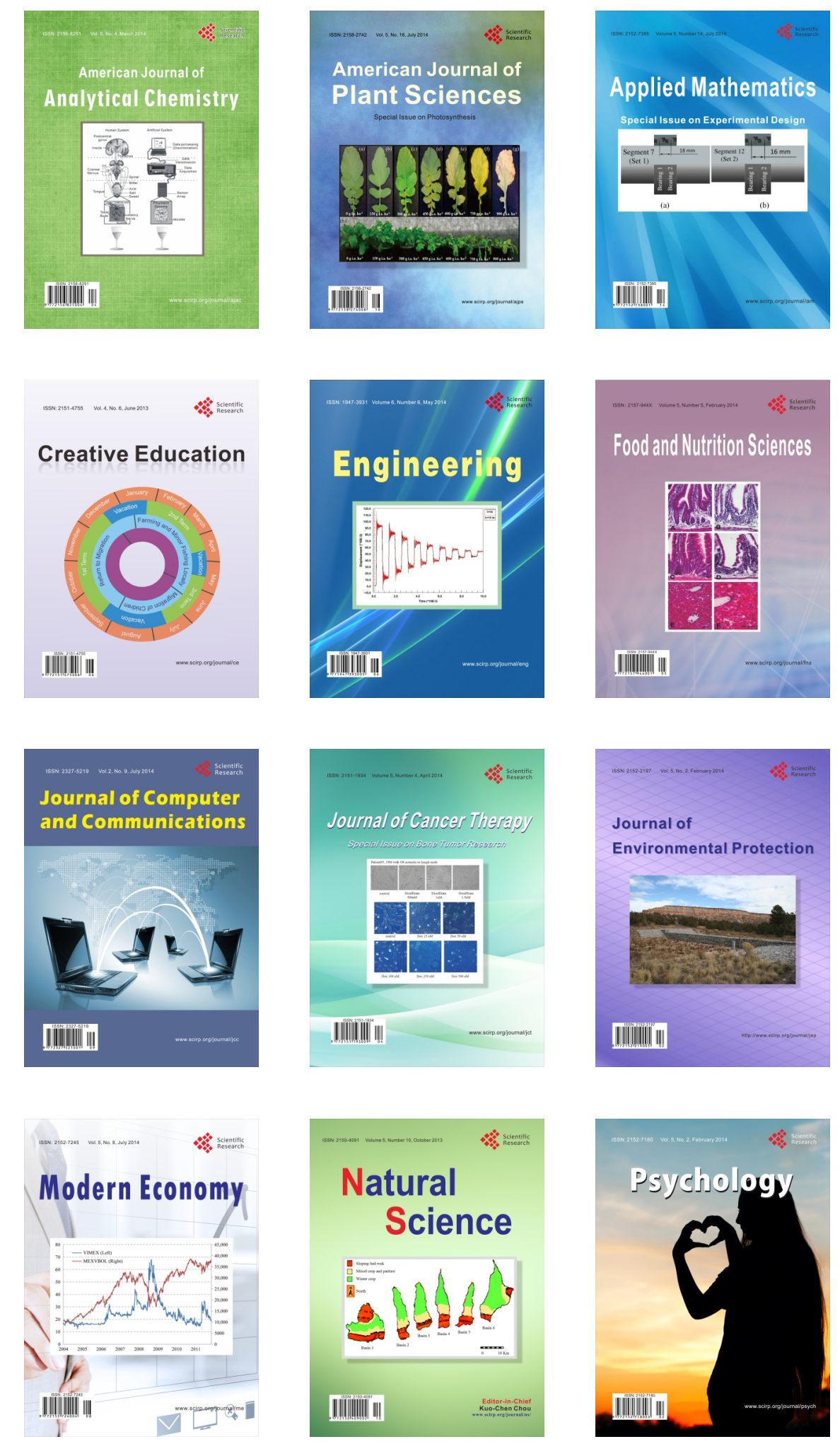